\title{
ESTRATÉGIAS DE ESTUDO E APRENDIZAGEM DE ESTUDANTES BRASILEIROS EM CURSOS DE FORMAÇÃO DE PROFESSORES
}

\begin{abstract}
Resumo
Esta investigação faz parte de uma pesquisa em andamento realizada em intercâmbio interinstitucional com várias universidades no Brasil, uma nos Estados Unidos e uma em Portugal. Seus principais objetivos são identificar as estratégias de estudo e aprendizagem de estudantes universitários brasileiros de uma instituição pública de ensino do estado de São Paulo e analisá-las em relação às variáveis sociodemográficas e de vida acadêmica dos estudantes. O estudo incluiu 163 estudantes universitários matriculados em programas de formação de professores. Os dados foram coletados com o Inventário de Estratégias de Aprendizagem e Estudo (LASSI - $3^{a}$ edição) - traduzido e adaptado para uso no Brasil - e um questionário sociodemográfico. Procedimentos estatísticos descritivos e inferenciais foram empregados para a análise dos dados. Os alunos responderam à pesquisa na Plataforma Autorregular desenvolvida para a pesquisa. No geral, os alunos relataram usar uma gama de estratégias de aprendizagem e estudo moderadamente, o que, na pontuação da escala LASSI, significa perto do ponto médio da escala de resposta de cinco pontos. Foram encontradas relações significativas entre as escalas LASSI e as variáveis sociodemográficas e de vida acadêmica. Esperamos que os dados coletados no presente estudo possam contribuir para o aumento do conhecimento sobre fatores que promovem a aprendizagem autorregulada $e$ capacitam os alunos para o sucesso no Ensino Superior no Brasil.
\end{abstract}

Palavras-chave: Autorregulação da Aprendizagem. Estudantes Universitários. Estratégias de Aprendizagem. Formação de Professores. 